Thabiea : Journal of Natural Science Teaching
Program Studi Tadris Ilmu Pengetahuan Alam
$\begin{aligned} & \text { Institut Agama Islam Negeri Kudus } \\ & \text { http://journal.stainkudus.ac.id/index.php/Thabiea } \\ & p \text {-issn: } 2580-8974, \text { e-issn: } 2655-898 x\end{aligned}$

\title{
Efektivitas Pembelajaran Biologi Berorientasi Literasi Saintifik
}

\section{Adib Rifqi Setiawan}

Madrasah Aliyah Tasywiquth Thullab Salafiyyah (TBS), J1. KH. Turaichan Adjhuri No. 23 Kudus, Indonesia, 59315 alobatnic@gmail.com

\begin{tabular}{ll}
\hline Kata kunci: & ABSTRAK \\
\hline literasi saintifik & Penelitian ini bertujuan untuk menemukan keefektifan pendekatan \\
pembelajaran biologi & saintifik dalam pembelajaran biologi berorientasi literasi saintifik. Subjek \\
pendekatan saintifik & dari penelitian ini adalah siswa program ilmu pengetahuan alam sekolah \\
& menengah di Kudus. Keefektifan diukur berdasarkan nilai ukuran efek \\
& Cohen $d$ berdasarkan hasil pretest dan posttest yang diambil menggunakan \\
& desain deret waktu. Hasil penelitian menunjukkan bahwa keefektifan \\
& pendekatan saintifik dalam pembelajaran biologi berorientasi literasi \\
& saintifik berada di kategori sedang dengan nilai 0,548. Pendekatan \\
& saintifik dapat menjadi tawaran model pembelajaran berorientasi literasi \\
& saintifik serta tidak dapat ditemukan model terbaik untuk digunakan \\
& dalam pembelajaran ilmu pengetahuan alam termasuk biologi.
\end{tabular}

\begin{tabular}{ll}
\hline Keyword: & ABSTRACT \\
biology learning & Effectiveness of biology learning scientific literacy oriented. The goals \\
scientific approach & of this work were to find the effectiveness of scientific approach in \\
scientific literacy & scientific literacy biological learning oriented. The subject of this study is \\
students of natural science program class in secondary school in Kudus. & To reveal effectiveness is measured based on the value of Cohen's d effect \\
size based on pretest and posttest result gained with time series design. & The results of this work revealed that the effectiveness of scientific \\
approach in scientific literacy biological learning oriented were in medium \\
category with the value were 0,548. Scientific approach can be used as \\
alternative model for scientific literacy learning oriented nor did not found \\
the best model for science learning include biology.
\end{tabular}

Copyright (C) 2019 Institut Agama Islam Negeri Kudus. All Right Reserved

\section{Pendahuluan}

Pembelajaran yang bertujuan untuk meningkatkan kemampuan siswa secara optimal harus dilakukan melalui langkah terstruktur dan terukur (Setiawan \& Koimah, 2019). Struktur pembelajaran yang baik diterapkan secara bertahap mulai dari langkah sederhana sampai rumit. Seluruh langkah tersebut dibuat agar dapat diukur, baik dari sisi pelaksanaan maupun pencapaian. Hal ini berlaku secara umum, termasuk dalam pembelajaran Ilmu Pengetahuan Alam (IPA) seperti biologi, fisika, kimia, geologi, dan astronomi. Salah satu cara untuk menyusun pembelajaran yang sesuai dengan prinsip tersebut ialah menggunakan pendekatan saintifik.

Pendekatan saintifik adalah pendekatan pedagogis yang menggunakan langkah sesuai dengan metode ilmiah (Setiawan, 2019). Nurohmah (2015) melalui one-group pretestposttest menemukan bahwa pendekatan saintifik mempunyai keefektifan tinggi dalam meningkatkan hasil belajar tiap aspek kognitif siswa pada jenjang pengetahuan, pemahaman, dan penerapan. Setiawan (2017) kemudian menerapkan pendekatan saintifik dalam pembelajaran fisika berorientasi literasi saintifik. Hasil yang diperoleh menggunakan one-group pretest-posttest menyebutkan bahwa pendekatan saintifik dalam pembelajaran fisika 
topik mekanika dapat meningkatkan literasi saintifik siswa di kategori sedang dengan nilai gain yang dinormalisasi sebesar 0,61 .

Nurohmah (2015) berupaya untuk mengetahui seberapa besar keefektifan pendekatan saintifik dalam meningkatkan hasil belajar. Besar keefektifan diukur berdasarkan ukuran efek Cohen $d$ terhadap hasil pretest dan posttest. Hasil pretest dan posttets diambil menggunakan tes objektif sebanyak 20 butir soal yang disusun sebagai alat pengukur hasil belajar tiap aspek kognitif. Tes tersebut diberikan kepada siswa sebelum dan sesudah pembelajaran sebanyak 3 pertemuan. Sementara tujuan penelitian Setiawan (2017) ialah untuk mendapat gambaran peningkatan literasi saintifik setelah diterapkan pendekatan saintifik dalam pembelajaran fisika topik mekanika. Penerapan tersebut dilakukan menggunakan desain pembelajaran yang diadaptasi dari usulan Utari, dkk. (2015). Peningkatan literasi saintifik diukur berdasarkan nilai gain yang dinormalisasi terhadap hasil pretest dan posttest. Alat ukur pretest dan posttets berupa tes tipe uraian sebanyak 18 butir soal yang disusun berdasarkan indikator kompetensi literasi saintifik dari Programme for International Student Assessment (PISA). Tes tersebut diberikan kepada siswa sebelum dan sesudah pembelajaran sebanyak 3 pertemuan.

Dari penyampaian informasi tersebut tampak bahwa pembelajaran yang dilaksanakan oleh Nurohmah (2015) tidak diarahkan untuk melatih literasi saintifik sepertihalnya dilakukan oleh Setiawan (2017). Namun, Setiawan (2017) luput tidak mengulas keefektifan penerapan pendekatan saintifik dalam pembelajaran laiknya dikerjakan oleh Nurohmah (2015). Ditilik dari sisi metode penelitian, keduanya menggunakan desain yang sama berupa onegroup pretest-posttest. Desain tersebut termasuk dalam tipe experimental dari kelompok weak experimental karena tidak memiliki kontrol untuk ancaman terhadap kualitas pelaksanaan rancangan penelitian, sehingga hasilnya bukan semata dipengaruhi oleh tindakan yang diberikan (Fraenkel \& Wallen, 2009). Keabsahan hasil penelitian tipe experimental akan lebih kuat kalau menggunakan dari kelompok true experimental lantaran peneliti dapat mengontrol beberapa faktor yang tidak diharapkan memengaruhi hasil penelitian.

Berdasarkan tuturan tersebut, kami memandang perlu dilakukan tindak lanjut terhadap Nurohmah (2015) dan Setiawan (2017) berupa penelitian yang memaduan tujuan dan pembahasan data serta perbaikan desain penelitian dari keduanya. Sehingga kami menerapkan pendekatan saintifik dalam pembelajaran biologi berorientasi literasi saintifik siswa. Karena itu rumusan masalah yang menjadi fokus kami ialah, "Bagaimana keefektifan pendekatan saintifik dalam pembelajaran biologi berorientasi literasi saintifik?"

\section{Metode}

Tujuan penelitian ini ialah untuk menemukan keefektifan pendekatan saintifik dalam pembelajaran biologi berorientasi literasi saintifik. Karena itu dibutuhkan data berupa profil literasi saintifik sebelum dan sesudah pembelajaran biologi menggunakan pendekatan saintifik. Berdasarkan tujuan penelitian dan kebutuhan data, metode penelitian yang dapat dipakai ialah pendekatan kualitatif tipe experimental jenis action research (Fraenkel \& Wallen, 2009). Dalam metode ini dapat digunakan kelompok desain quasiexperimental, yang kami pilih karena kesulitan menggunakan true experimental, tapi hasilnya lebih kuat daripada weak eksperimental.

Desain penelitian yang dipilih dari kelompok quasi-experimental yakni time series, karena tidak memerlukan kelompok kontrol untuk dibandingkan dengan kelompok eksperimen, tidak menggunakan penyamaan karakteristik dalam satu kelompok tindakan, serta tidak memerlukan pengontrol variabel. Untuk desain time series, kelompok yang digunakan untuk penelitian tidak dapat dipilih secara random sampling, sehingga sampel diambil menggunakan teknik convenience sampling (Fraenkel \& Wallen, 2009). Target 
populasi di sini adalah siswa sekolah menengah program ilmu pengetahuan alam (IPA) di Kabupaten Kudus. Sampel yang diambul sebanyak 120 siswa dengan kisaran usia 15-17 tahun dari salah satu sekolah menengah.

Desain penelitian berupa 16 kali pengamatan terhitung mulai 6 Januari sampai 3 Maret 2019. Rincian desain yakni: 8 kali pengamatan sebelum diberikan tindakan berupa hasil pretest $\left(\mathrm{O}_{\mathrm{A} 1}, \mathrm{O}_{\mathrm{A} 2}, \mathrm{O}_{\mathrm{A} 3}, \mathrm{O}_{\mathrm{A} 4}, \mathrm{O}_{\mathrm{A} 5}, \mathrm{O}_{\mathrm{A} 6}, \mathrm{O}_{\mathrm{A} 7}\right.$, $\left.\mathrm{O}_{\mathrm{A} 8}\right) ; 8$ kali pengamatan setelah diberikan tindakan berupa hasil posttest $\left(\mathrm{O}_{\mathrm{H} 1}, \mathrm{O}_{\mathrm{H} 2}, \mathrm{O}_{\mathrm{H} 3}\right.$, $\mathrm{O}_{\mathrm{H} 4}, \mathrm{O}_{\mathrm{H} 5}, \mathrm{O}_{\mathrm{H} 6}, \mathrm{O}_{\mathrm{H} 7}, \mathrm{O}_{\mathrm{H} 8}$ ); serta tindakan berupa penerapan pendekatan saintifik yang dilaksanakan secara malar dalam pembelajaran biologi topik plantae meliputi bryophyta $\left(\mathrm{P}_{1}\right)$, pteridophyta $\left(\mathrm{P}_{2}\right)$, gymnospermae $\left(\mathrm{P}_{3}\right)$, dan angiospermae $\left(\mathrm{P}_{4}\right)$ serta animalia mencakup annelida $\left(\mathrm{P}_{5}\right)$, arthropoda $\left(\mathrm{P}_{6}\right)$, pisces $\left(\mathrm{P}_{7}\right)$, dan tetrapoda $\left(\mathrm{P}_{8}\right)$. Desain tersebut ditunjukkan dengan pola berikut:

$\begin{array}{lll}\mathrm{O}_{\mathrm{A} 1} & \Rightarrow \mathrm{P}_{1} \Rightarrow & \mathrm{O}_{\mathrm{H} 1} \\ \mathrm{O}_{\mathrm{A} 2} & \Rightarrow \mathrm{P}_{2} \Rightarrow & \mathrm{O}_{\mathrm{H} 2} \\ \mathrm{O}_{\mathrm{A} 3} & \Rightarrow \mathrm{P}_{3} \Rightarrow & \mathrm{O}_{\mathrm{H} 3} \\ \mathrm{O}_{\mathrm{A} 4} & \Rightarrow \mathrm{P}_{4} \Rightarrow & \mathrm{O}_{\mathrm{H} 4} \\ \mathrm{O}_{\mathrm{A} 5} & \Rightarrow \mathrm{P}_{5} \Rightarrow & \mathrm{O}_{\mathrm{H} 5} \\ \mathrm{O}_{\mathrm{A} 6} & \Rightarrow \mathrm{P}_{6} \Rightarrow & \mathrm{O}_{\mathrm{H} 6} \\ \mathrm{O}_{\mathrm{A} 7} & \Rightarrow \mathrm{P}_{7} \Rightarrow & \mathrm{O}_{\mathrm{H} 7} \\ \mathrm{O}_{\mathrm{A} 8} & \Rightarrow \mathrm{P}_{8} \Rightarrow & \mathrm{O}_{\mathrm{H} 8}\end{array}$

Penerapan pendekatan saintifik dilaksanakan menggunakan desain pembelajaran usulan Utari, dkk. (2015) yang diperbaiki oleh Setiawan (2017). Komponen literasi saintifik yang dilatih untuk setiap langkah berfokus kepada domain kompetensi, ialah: menjelaskan fenomena secara ilmiah (K1), merancang dan mengevaluasi penyelidikan ilmiah (K2), dan menafsirkan data dan bukti secara ilmiah (K3).

Instrumen yang dipakai untuk mengukur literasi saintifik berupa tes tipe uraian dengan konten terkait topik bryophyta, pteridophyta, gymnospermae, angiospermae, annelida, arthropoda, pisces, dan tetrapoda masingmasing sebanyak 3 butir soal yang disusun berdasarkan indikator kompetensi dari kerangka kerja PISA.

Tabel 1. Indikator Kompetensi Literasi Saintifik

\begin{tabular}{|c|c|c|}
\hline Kompetensi & Kode & Indikator \\
\hline $\begin{array}{l}\text { Menjelaskan fenomena } \\
\text { secara ilmiah }\end{array}$ & $\mathrm{K} 1$ & $\begin{array}{l}\text { Mengingat dan menerapkan pengetahuan ilmiah yang sesuai } \\
\text { Mengidentifikasi, menggunakan, serta menghasilkan model dan } \\
\text { representasi yang jelas } \\
\text { Menjelaskan implikasi potensial dari pengetahuan ilmiah bagi } \\
\text { masyarakat }\end{array}$ \\
\hline $\begin{array}{l}\text { Merancang dan } \\
\text { mengevaluasi penyelidikan } \\
\text { ilmiah }\end{array}$ & $\mathrm{K} 2$ & $\begin{array}{l}\text { Mengusulkan cara mengeksplorasi secara ilmiah terhadap pertanyaan } \\
\text { yang diberikan } \\
\text { Mengevaluasi cara mengeksplorasi secara ilmiah pertanyaan yang } \\
\text { diberikan } \\
\text { Mendeskripsikan dan mengevaluasi berbagai cara yang digunakan oleh } \\
\text { ilmuan untuk menentukan keabsahan dan keobjektifan data serta } \\
\text { keumuman penjelasan }\end{array}$ \\
\hline $\begin{array}{l}\text { Menafsirkan data dan bukti } \\
\text { secara ilmiah }\end{array}$ & $\mathrm{K} 3$ & $\begin{array}{l}\text { Mengubah data dari satu representasi ke representasi yang lain } \\
\text { Menganalisis dan menafsirkan data dan menarik kesimpulan yang tepat }\end{array}$ \\
\hline
\end{tabular}

(OECD, 2018) 
Tabel 2. Kompetensi yang dilatihkan untuk Setiap Langkah Pembelajaran

\begin{tabular}{|c|c|c|c|}
\hline \multicolumn{2}{|c|}{ Langkah Pembelajaran } & \multirow{3}{*}{$\begin{array}{l}\text { Gambaran Kegiatan } \\
\text { Memberi contoh penerapan masalah keseharian } \\
\text { terkait dengan konsep yang akan disampaikan. }\end{array}$} & \multirow{2}{*}{$\begin{array}{l}\text { Literasi } \\
\text { Saintifik }\end{array}$} \\
\hline Kegiatan & Apersepsi & & \\
\hline Pendahuluan & Motivasi & & K1 \\
\hline \multirow{5}{*}{ Kegiatan Inti } & Mengamati & $\begin{array}{l}\text { Melakukan simpulan dari hasil pengamatan, } \\
\text { mendapatkan data untuk memunculkan } \\
\text { pertanyaan penyelidikan. }\end{array}$ & $\mathrm{K} 1, \mathrm{~K} 3$ \\
\hline & Menanya & $\begin{array}{l}\text { Mengajukan pertanyaan penyelidikan terkait } \\
\text { objek yang dimati, memprediksi hubungan antar } \\
\text { variabel. }\end{array}$ & $\mathrm{K} 1, \mathrm{~K} 2$ \\
\hline & $\begin{array}{l}\text { Mengumpulkan Informasi } \\
\text { (pustaka) }\end{array}$ & $\begin{array}{l}\text { Merencanakan eksperimen, melakukan } \\
\text { eksperimen, mengumpulkan informasi pustaka } \\
\text { yang relevan. }\end{array}$ & $\mathrm{K} 1, \mathrm{~K} 2, \mathrm{~K} 3$ \\
\hline & $\begin{array}{l}\text { Mengolah Data } \\
\text { (laboratorium atau } \\
\text { lapangan) }\end{array}$ & Menganalisis data dan membuat kesimpulan. & $\mathrm{K} 2, \mathrm{~K} 3$ \\
\hline & Mengomunikasikan Hasil & $\begin{array}{l}\text { Menyampaikan kesimpulan yang didapatkan } \\
\text { secara lisan dan tulisan. }\end{array}$ & $\mathrm{K} 2, \mathrm{~K} 3$ \\
\hline \multirow{2}{*}{$\begin{array}{l}\text { Kegiatan } \\
\text { Penutup }\end{array}$} & Evaluasi & $\begin{array}{l}\text { Memberi soal terkait dengan konsep yang telah } \\
\text { dibahas. }\end{array}$ & $\mathrm{K} 1, \mathrm{~K} 2, \mathrm{~K} 3$ \\
\hline & Penugasan & $\begin{array}{l}\text { Memberi tugas yang memacu siswa untuk } \\
\text { menuangkan gagasan dalam memecahkan } \\
\text { masalah keseharian. }\end{array}$ & $\mathrm{K} 1, \mathrm{~K} 2, \mathrm{~K} 3$ \\
\hline
\end{tabular}

Tabel 3. Sebaran Topik Instrumen Pengukuran

\begin{tabular}{|c|c|c|}
\hline Topik & Rincian & Penggunaan \\
\hline \multirow[t]{4}{*}{ Plantae } & Bryophyta & $\mathrm{O}_{\mathrm{A} 1} \operatorname{dan} \mathrm{O}_{\mathrm{H} 1}$ \\
\hline & Pteridophyta & $\mathrm{O}_{\mathrm{A} 2}$ dan $\mathrm{O}_{\mathrm{H} 2}$ \\
\hline & Gymnospermae & $\mathrm{O}_{\mathrm{A} 3}$ dan $\mathrm{O}_{\mathrm{H} 3}$ \\
\hline & Angiospermae & $\mathrm{O}_{\mathrm{A} 4}$ dan $\mathrm{O}_{\mathrm{H} 4}$ \\
\hline \multirow[t]{4}{*}{ Animalia } & Annelida & $\mathrm{O}_{\mathrm{A} 5}$ dan $\mathrm{O}_{\mathrm{H} 5}$ \\
\hline & Arthropoda & $\mathrm{O}_{\mathrm{A} 6}$ dan $\mathrm{O}_{\mathrm{H} 6}$ \\
\hline & Pisces & $\mathrm{O}_{\mathrm{A} 7}$ dan $\mathrm{O}_{\mathrm{H} 7}$ \\
\hline & Tetrapoda & $\mathrm{O}_{\mathrm{A} 8}$ dan $\mathrm{O}_{\mathrm{H} 8}$ \\
\hline
\end{tabular}

(OECD, 2018)

Keabsahan instrumen ditentukan berdasarkan validasi pakar, masing-masing terhadap kesesuaian indikator dengan soal, kesesuaian jawaban dengan pertanyaan, serta kesesuaian soal dengan jenjang sekolah. Pakar yang dipilih yaitu akademisi dengan bidang kepakaran literasi saintifik dan evaluasi pembelajaran biologi serta praktisi pembelajaran biologi sekolah menengah dan bidang profesional terkait biologi.

Sementara keandalan instrumen ditentukan berdasarkan internal consistency. Dengan cara ini, dibutuhkan satu kali uji coba yang hasilnya diolah dengan ketentuan instrumen dapat digunakan kalau nilai koefisien keandalan persamaan Kuder-Richardson 
Approaches (KR20) lebih besar dari 0,70 (Fraenkel \& Wallen, 2009; Cronbach, 1951).

Setelah dilakukan validasi kepada 4 pakar dan uji coba terhadap 40 siswa ditemukan bahwa instrumen layak dipakai serta nilai koefisien keabsahan memenuhi kriteria dapat digunakan.

Dalam mengukur literasi saintifik siswa, digunakan panduan penilaian jawaban berikut:

Tabel 4. Klasifikasi Skor Setiap Jawaban

\begin{tabular}{cl}
\hline Skor & \multicolumn{1}{c}{ Jawaban } \\
\hline 3 & Sesuai seperti yang diharapkan \\
2 & $\begin{array}{l}\text { Hampir seperti yang diharapkan tanpa } \\
\text { terdapat pernyataan yang salah }\end{array}$ \\
1 & $\begin{array}{l}\text { Mengandung hal yang benar dan terdapat } \\
\text { pula pernyataan yang salah }\end{array}$ \\
0 & $\begin{array}{l}\text { Jawaban tidak berhubungan dengan } \\
\text { pertanyaan yang diajukan }\end{array}$ \\
0 & Tidak menjawab \\
\hline
\end{tabular}

Dari skor tersebut, keefektifan dicari melalui perhitungan nilai ukuran efek (effect size) dari nilai Cohen $d$ (Nissen, dkk., 2018). Hasil perhitungan tersebut kemudian ditafsirkan berdasarkan tabel berikut:

Tabel 5. Besar Keefektifan

\begin{tabular}{cc}
\hline Nilai & Kategori \\
\hline 0,01 & Sangat Kecil \\
0,20 & Kecil \\
0,50 & Sedang \\
0,80 & Tinggi \\
1,20 & Sangat Tinggi \\
2,00 & Luar Biasa \\
\hline & (Sawilowsky, 2009)
\end{tabular}

\section{Hasil dan pembahasan}

Hasil penelitian ditunjukkan melalui gambar 1, yang menampakkan bahwa terdapat peningkatan hasil dari pretest ke posttest. Hasil yang diperoleh dari pretest tidak stabil dengan bentuk garis memenuhi persamaan persamaan $y=-0,0045 x+0,6179, \quad$ tapi karena memiliki rentang perbedaan yang kecil dapat dikatakan bahwa ketidakstabilan kurang signifikan. Ketidakstabilan serupa juga diperoleh dari hasil posttest memenuhi persamaan $\quad y=-0,0152 x+1,4886$. Persamaan garis $y=0,075 x+0,3717$ diperoleh untuk keseluruhan tahap pengamatan. Koefisien positif dalam persamaan tersebut menyampaikan makna bahwa terdapat kecenderungan peningkatan nilai dari setiap tahap. Perhitungan hasil tersebut memberi nilai Cohen $d$ sebesar 0,548, yang berarti secara keseluruhan penerapan pendekatan saintifik dalam pembelajaran biologi berorientasi literasi saintifik memiliki keefektifan di kategori sedang.

Dapat dilihat dari Gambar 1 bahwa pendekatan saintifik terbilang efektif untuk melatih literasi saintifik dalam pembelajaran biologi. Hasil ini menguatkan Nurohmah (2015) yang mengungkap bahwa pendekatan saintifik efektif dalam meningkatkan hasil belajar tiap aspek kognitif siswa pada jenjang pengetahuan, pemahaman, dan penerapan. Namun, kategori keefektifan yang didapat oleh Nurohmah (2015) berada di kategori tinggi, sedangkan kami berada di kategori sedang. Hal ini mungkin disebabkan oleh indikator hasil belajar yang dirancang dalam pembelajaran. Nurohmah (2015) merancang pembelajaran berdasarkan aspek kognitif tanpa mengaitkan dengan literasi saintifik seperti yang kami lakukan. Kemungkinan tersebut didukung oleh temuan PISA yang menyebutkan bahwa ratarata skor literasi saintifik siswa Indonesia sebesar 403, lebih rendah 90 poin dari rata-rata internasional sebesar 493 serta jauh di bawah peringkat pertama yakni Singapura dengan ratarata 556 poin (OECD, 2018). 


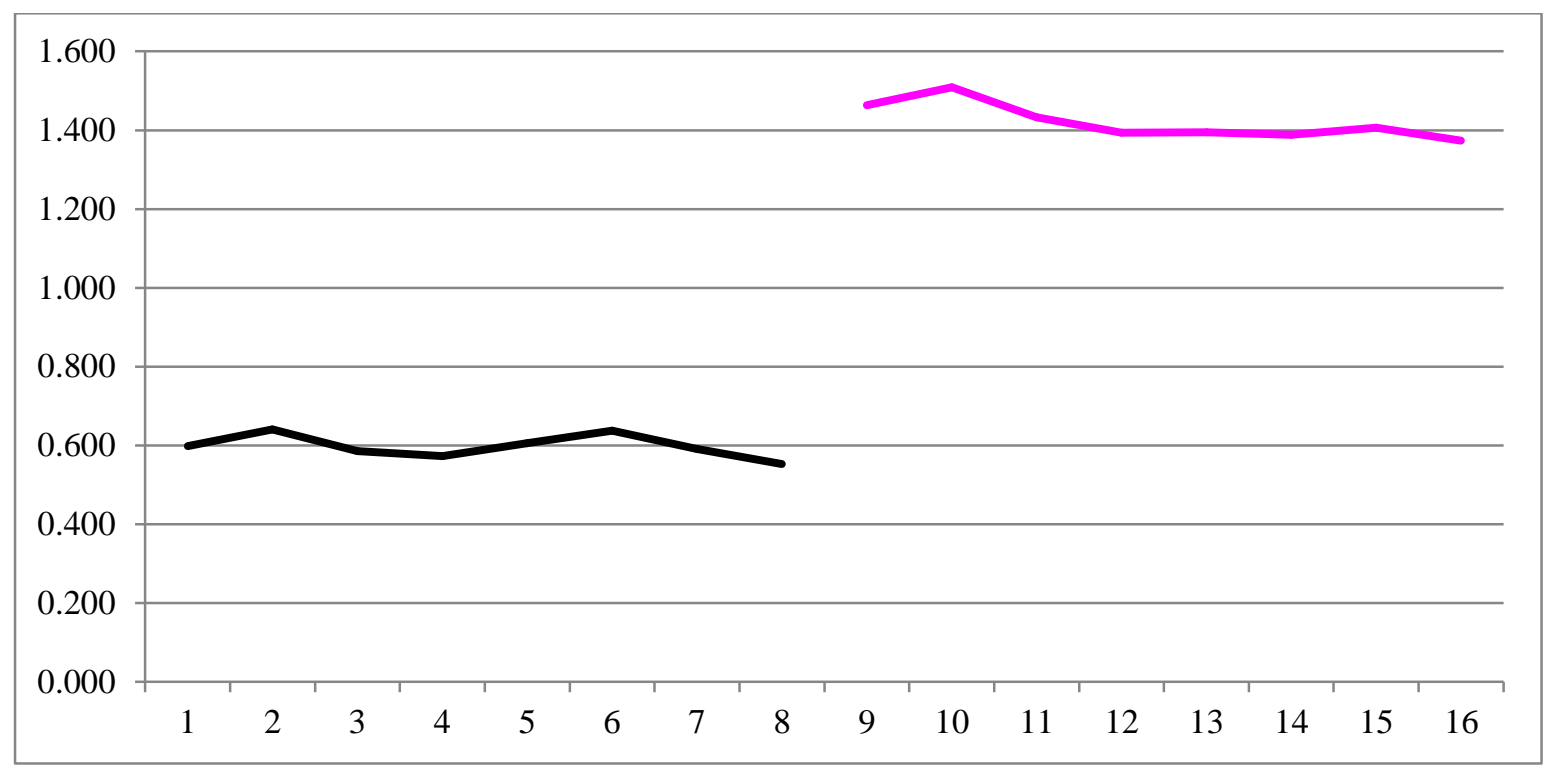

Gambar 1. Kecenderungan data dari tahap pretest (black) ke posttest (pink)

Temuan PISA berbanding terbalik dengan pendapat Suwarma (2012), yang melalui kajian deskriptif terhadap kurikulum Indonesia sejak 1947 sampai 2006 menyampaikan bahwa kualitas pendidikan di Indonesia mulai meningkat secara bertahap dilihat dari persentase siswa yang lulus ujian nasional (UN). Anggapan berdasarkan hasil UN ini dapat memberi kesimpulan bahwa hasil pembelajaran IPA di Indonesia sudah bagus. Artinya ketika acuan penilaian hasil pembelajaran IPA berupa ujian nasional dengan susunan indikator berdasarkan rincian aspek kognitif, diperoleh kesimpulan lebih baik daripada menggunakan indikator literasi saintifik. Hasil ini selaras dengan perbandingan hasil yang kami peroleh dengan temuan Nurohmah (2015).

Penilaian dari PISA memang bukan harga mati dalam mengukur hasil pembelajaran. Pasalnya PISA hanya menunjukkan umur sampel tanpa menyampaikan wilayah sekolah yang menjadi lokasi pengambilan data. Aspek wilayah terbilang penting karena Indonesia masih memiliki masalah kesenjangan pendidikan antar wilayah. Sehingga penilaian di wilayah tertentu misalnya di Bandung, dengan di wilayah lain seperti Malang, memungkinkan hasil yang berbeda. Meski demikian, bukan berarti penilaian PISA tidak perlu diperhatikan sama sekali. Selain menyediakan informasi sebagai bahan evaluasi pembelajaran di beberapa negara, PISA juga memberikan kerangka kerja yang digunakan dasar pengukuran. Kerangka kerja dari PISA dapat diadopsi atau minimal diadaptasi ke dalam proses pembelajaran karena menekankan kemampuan siswa untuk menerapkan hasil pembelajaran terhadap masalah keseharian. Kerangka kerja tersebut secara ringkas dapat disebut dengan literasi saintifik.

Corebima (2016) mengungkap fakta berupa pembelajaran dilakukan mengacu pada acuan utama, yaitu supaya para siswa lulus ujian, yang membuat guru berupaya dengan segala cara, baik halal maupun setengah halal, agar siswa memahami sajian konten pembelajaran sementara siswa juga berupaya dengan segala cara serupa agar dapat menjawab soal ujian sehingga dinyatakan lulus. Artinya fakta di lapangan menunjukkan bahwa ketika ujian nasional, yang menjadi dasar Suwarma (2012) dalam mengungkap pendapat, cenderung berupaya menumpuk pengetahuan ketimbang memupuk keterampilan. Hal ini berbeda kalau acuan utama yang digunakan ialah literasi saintifik. Rustaman (2017) menyebutkan bahwa pembelajaran IPA, termasuk biologi, berorientasi literasi saintifik dapat dilakukan dengan cara mengkaji indikator guna dibekalkan kepada siswa, bukan sekadar membiasakan berlatih soal menurut PISA. Dari 
sini tampak bahwa pembelajaran berorientasi literasi saintifik lebih berupaya memupuk keterampilan ketimbang menumpuk pengetahuan.

Utari, dkk. (2015) menyediakan hasil bagus berupa matriks kaitan antara literasi saintifik untuk domain pengetahuan dan kompetensi dengan langkah pembelajaran berdasarkan Kurikulum Tingkat Satuan Pendidikan (KTSP) dan Kurikulum 2013 (K13). Nilai penting dari karya Utari, dkk. (2015) ialah menyediakan panduan operasional dalam menyusun desain pembelajaran berorientasi literasi saintifik. Panduan tersebut kemudian diadaptasi dalam bentuk matriks oleh Setiawan (2017) untuk menerapkan pendekatan saintifik dalam pembelajaran fisika berorientasi literasi saintifik. Walau sayang seperti telah disebutkan sebelumnya, Setiawan (2017) luput tidak mengulas keefektifan penerapan pendekatan saintifik dalam pembelajaran. Selain itu, baik Utari, dkk. (2015) maupun Setiawan (2017), memperoleh profil literasi saintifik dalam pembelajaran fisika, bukan biologi. Untuk itulah diperlukan penelitian berlanjut di luar topik fisika seperti yang kami lakukan melalui desain time series dalam pembelajaran biologi ini, walau untuk saat ini keefektifan yang diperoleh belum mencapai kategori tinggi.

Desain time series dalam praktiknya sama seperti dengan penelitian tindakan kelas (PTK), tapi tanpa terdapat tahap refleksi. Melalui PTK yang terdiri dari 4 siklus Wahyuni (2018) memperoleh kesimpulan bahwa penerapan pendekatan saintifik dapat meningkatkan aspek pengetahuan dan keterampilan pada pelajaran biologi di sekolah menengah. Wahyuni (2018), laiknya Nurohmah (2015), tidak mengaitkan pembelajaran dengan literasi saintifik. Namun, perbandingan tersebut menunjukkan bahwa pendekatan saintifik dapat memberikan hasil belajar yang baik. Secara umum pendekatan saintifik tersusun dari beberapa langkah pembelajaran berurutan, ialah: mengamati, menanya, mengumpulkan informasi, melakukan percobaan, mengolah data, serta mengomunikasikan hasil.
Pendekatan saintifik dipakai guna memberi pengalaman kepada siswa agar hasil yang diperoleh dapat absah, andal, dan objektif melalui langkah pembelajaran terstruktur dan terukur. Struktur pembelajaran diterapkan secara bertahap mulai dari langkah sederhana sampai rumit dengan langkah yang dapat diukur, baik dari sisi pelaksanaan maupun pencapaian. Rustaman (2017) menyebut bahwa dalam pembelajaran IPA selayaknya terdapat kegiatan yang membekali siswa untuk mengembangkan operasi mereka menjadi sesuatu yang lebih bermakna dalam memahami pola di alam dan hakikat sains sekaligus melatih keterampilan ilmiah serta menumbuhkan kepedulian terhadap alam dan upaya pelestarian fungsinya. Dari sini dapat dikatakan bahwa langkah pendekatan saintifik mendukung pembelajaran IPA.

Kompetensi merancang dan mengevaluasi penyelidikan ilmiah mengalami nilai keefektifan paling tinggi, yang secara berurutan diikuti oleh menjelaskan fenomena secara ilmiah kemudian menafsirkan data dan bukti secara ilmiah. Hasil yang ditampilkan dalam Tabel 6 menunjukkan bahwa pendekatan saintifik lebih efektif dalam melatih siswa untuk merancang dan mengevaluasi penyelidikan ilmiah daripada menjelaskan fenomena serta menafsirkan data dan bukti secara ilmiah. Hasil ini memiliki perbedaan dengan dengan Setiawan (2017) yang memberi informasi bahwa peningkatan literasi saintifik untuk pembelajaran fisika topik mekanika berada di kategori sedang dengan urutan: menafsirkan data dan bukti secara ilmiah, merancang dan mengevaluasi penyelidikan ilmiah, dan menjelaskan fenomena secara ilmiah. Perbandingan hasil tersebut menunjukkan bahwa peningkatan untuk kompetensi menjelaskan fenomena secara ilmiah dan merancang dan mengevaluasi penyelidikan ilmiah untuk topik biologi lebih tinggi daripada fisika, tapi hal ini berlaku sebaliknya untuk kompetensi menjelaskan fenomena serta menafsirkan data dan bukti secara ilmiah. Tampak bahwa siswa lebih sulit 
menafsirkan data dan bukti secara ilmiah di topik biologi daripada fisika.

Tabel 6. Rincian Keefektifan

\begin{tabular}{ccc}
\hline \multirow{2}{*}{ Kompetensi } & \multicolumn{2}{c}{ Keefektifan } \\
\cline { 2 - 3 } & Nilai & Kategori \\
\hline K1 & 0,555 & Sedang \\
K2 & 0,581 & Sedang \\
K3 & 0,509 & Sedang \\
\hline
\end{tabular}

Biologi memang disiplin ilmu yang rumit dibanding dengan cabang lain dalam IPA (Koimah \& Setiawan, 2019). Marcharis (2015) menyebut bahwa biologi kerap dianggap sebagai pelajaran hafalan yang membuat siswa cenderung merasa berat dalam mempelajari. Melalui kajian deskriptif terungkap bahwa siswa di pondok pesantren memiliki kemampuan menerima dan mengolah informasi yang termasuk ke dalam kategori sedang, hanya menggunakan sedikit usaha mentalnya dalam mempelajari materi biologi di dalam kelas, serta hasil belajar termasuk ke dalam kategori kurang. Nilai penting dari gambaran yang didapat oleh Marcharis (2015) ialah menunjukkan bahwa terdapat perjuangan berat bagi guru biologi untuk memandu pembelajaran seiring topik yang dibahas memiliki kerumitan. Kerumitan biologi cukup berbahaya karena ketika topik pembelajaran terlampau rumit siswa dapat mengalami beban kognitif, tapi pada saat bersamaan ketika hal ini disampaikan secara sederhana membuka peluang timbulnya kesalahpahaman serta mempromosikan hafalan bukan pemahaman (Koimah \& Setiawan, 2019; Si'ayah, 2010).

Literasi saintifik tampak tidak terkait maupun identik dengan topik tertentu. Hal ini diperlihatkan oleh temuan yang menunjukkan bahwa pembelajaran memiliki keefektifan relatif setara meski berbeda topik untuk kompetensi merancang dan mengevaluasi penyelidikan ilmiah. Dalam kompetensi ini, siswa tidak dikaitkan secara langsung dengan objek pengamatan dan/atau percobaan karena lebih menekankan terhadap penggunaan metode ilmiah. Walau begitu, kaitan antara semua kompetensi dengan setiap topik yang ditunjukkan melalui tabel 7 diperoleh keefektifan kategori sedang hampir di setiap rincian, kecuali kompetensi menjelaskan fenomena secara ilmiah di topik pisces serta kompetensi menafsirkan data dan bukti secara ilmiah di topik tetrapoda, yang keduanya mendapat keefektifan rendah. Hasil ini cenderung selaras dengan gambar 1 yang memperlihatkan bahwa pendekatan saintifik memiliki keefektifan berbeda untuk melatih kompetensi literasi saintifik di kategori sedang dengan nilai beragam untuk setiap topik. Secara beruntun urutannya ialah: pteridophyta $\left(\mathrm{P}_{2}\right)$, bryophyta $\left(\mathrm{P}_{1}\right), \quad$ gymnospermae $\left(\mathrm{P}_{3}\right)$, angiospermae $\left(\mathrm{P}_{4}\right)$, tetrapoda $\left(\mathrm{P}_{8}\right)$, pisces $\left(\mathrm{P}_{7}\right)$, annelida $\left(\mathrm{P}_{5}\right)$, kemudian arthropoda $\left(\mathrm{P}_{6}\right)$. Urutan tersebut justru berbeda dengan pembelajaran yang dilaksanakan, secara malar yakni bryophyta $\left(\mathrm{P}_{1}\right), \quad$ pteridophyta $\left(\mathrm{P}_{2}\right)$, gymnospermae $\left(\mathrm{P}_{3}\right)$, dan angiospermae $\left(\mathrm{P}_{4}\right)$ serta animalia mencakup annelida $\left(\mathrm{P}_{5}\right)$, arthropoda $\left(\mathrm{P}_{6}\right)$, pisces $\left(\mathrm{P}_{7}\right)$, dan tetrapoda $\left(\mathrm{P}_{8}\right)$.

Keefektifan seperti itu menunjukkan bahwa dalam pembelajaran biologi pendekatan saintifik lebih efektif untuk melatih kompetensi literasi saintifik menggunakan topik plantae daripada topik animalia. Dalam proses pembelajaran secara umum, siswa diminta untuk mengamati organisme terkait topik yang sedang dipelajari. Misalnya untuk topik angiospermae $\left(\mathrm{P}_{4}\right)$, siswa diminta untuk mengamati mawar merah (Rosa centifolia) dengan fokus pengamatan terhadap bentuk akar, letak pembuluh angkut, bentuk tulang daun, serta pola bagian bunga. Dengan keefektifan pembelajaran di kategori sedang sebesar 0,547, diharapkan pembelajaran berikutnya yakni annelida $\left(\mathrm{P}_{5}\right)$ dapat lebih efektif dalam melatih siswa. Sayang dalam pembelajaran annelida menggunakan Cacing tanah (Lumbricus terrestris) yang fokus pengamatan terhadap jaringan tubuh, simetri tubuh, lapisan nutfah, dan tulang belakang justru memiliki keefektifan sedang sebesar 0,526. Artinya, keefektifan yang diperoleh dari pembelajaran angiospermae $\left(\mathrm{P}_{4}\right)$ terasa kurang berguna ketika memasuki topik annelida $\left(\mathrm{P}_{5}\right)$. 
Pasalnya dalam topik annelida, siswa harus berurusan dengan organisme yang lebih lentur, sehingga lebih menyulitkan mereka buat memotong setiap bagian organisme untuk mengamati lapisan nutfah. Hasil potongan pun akhirnya sulit untuk diamati, sehingga data yang diperoleh sulit untuk ditafsirkan. Keadaan seperti ini dikuatkan oleh temuan yang menunjukkan bahwa keefektifan pembelajaran dalam topik animalia untuk tetrapoda menggunakan Mencit (Mus musculus) dan pisces menggunakan Bandeng (Chanos chanos), yang lebih mudah dipotong, lebih tinggi dibandingkan dengan annelida menggunakan Cacing tanah (Lumbricus terrestris) dan arthropoda menggunakan Udang jerbung (Fenneropenaeus merguiensis).

Paparan hasil di Tabel 7 justru melemahkan anggapan bahwa literasi saintifik tidak identik dengan topik tertentu. Pasalnya perbedaan tingkat kerumitan antar topik ketika disampaikan dengan pendekatan yang sama dan diukur menggunakan indikator yang sama, hasilnya tampak berbeda. Kian rumit topik yang dibahas, keefektifan pembelajaran untuk

Tabel 7. Rincian Keefektifan

\begin{tabular}{|c|c|c|c|}
\hline \multirow{2}{*}{ Topik } & \multirow{2}{*}{ Kompetensi } & \multicolumn{2}{|c|}{ Keefektifan } \\
\hline & & Nilai & Kategori \\
\hline \multirow[t]{3}{*}{ Bryophyta } & Menjelaskan fenomena secara ilmiah & 0,620 & Sedang \\
\hline & Merancang dan mengevaluasi penyelidikan ilmiah & 0,596 & Sedang \\
\hline & Menafsirkan data dan bukti secara ilmiah & 0,515 & Sedang \\
\hline \multirow[t]{3}{*}{ Pteridophyta } & Menjelaskan fenomena secara ilmiah & 0,583 & Sedang \\
\hline & Merancang dan mengevaluasi penyelidikan ilmiah & 0,607 & Sedang \\
\hline & Menafsirkan data dan bukti secara ilmiah & 0,548 & Sedang \\
\hline \multirow[t]{3}{*}{ Gymnospermae } & Menjelaskan fenomena secara ilmiah & 0,556 & Sedang \\
\hline & Merancang dan mengevaluasi penyelidikan ilmiah & 0,567 & Sedang \\
\hline & Menafsirkan data dan bukti secara ilmiah & 0,571 & Sedang \\
\hline \multirow[t]{3}{*}{ Angiospermae } & Menjelaskan fenomena secara ilmiah & 0,516 & Sedang \\
\hline & Merancang dan mengevaluasi penyelidikan ilmiah & 0,592 & Sedang \\
\hline & Menafsirkan data dan bukti secara ilmiah & 0,535 & Sedang \\
\hline \multirow[t]{3}{*}{ Annelida } & Menjelaskan fenomena secara ilmiah & 0,560 & Sedang \\
\hline & Merancang dan mengevaluasi penyelidikan ilmiah & 0,517 & Sedang \\
\hline & Menafsirkan data dan bukti secara ilmiah & 0,503 & Sedang \\
\hline \multirow[t]{3}{*}{ Arthropoda } & Menjelaskan fenomena secara ilmiah & 0,484 & Rendah \\
\hline & Merancang dan mengevaluasi penyelidikan ilmiah & 0,607 & Sedang \\
\hline & Menafsirkan data dan bukti secara ilmiah & 0,413 & Rendah \\
\hline \multirow[t]{3}{*}{ Pisces } & Menjelaskan fenomena secara ilmiah & 0,520 & Sedang \\
\hline & Merancang dan mengevaluasi penyelidikan ilmiah & 0,580 & Sedang \\
\hline & Menafsirkan data dan bukti secara ilmiah & 0,531 & Sedang \\
\hline \multirow[t]{3}{*}{ Tetrapoda } & Menjelaskan fenomena secara ilmiah & 0,600 & Sedang \\
\hline & Merancang dan mengevaluasi penyelidikan ilmiah & 0,583 & Sedang \\
\hline & Menafsirkan data dan bukti secara ilmiah & 0,457 & Rendah \\
\hline
\end{tabular}

melatih literasi saintifik kian rendah. Karena itu dalam menyiapkan pembelajaran, urutan topik yang dibahas perlu diperhatikan secara seksama berdasarkan tingkat kerumitannya di mata siswa tanpa perlu terpaku dengan panduan dalam kurikulum yang diberlakukan. 
Dilihat dari sisi peningkatan tinggi dari kompetensi merancang dan mengevaluasi penyelidikan ilmiah, hasil yang kami peroleh sama seperti Dinata (2018) ketika melakukan field trip di topik ekosistem. Dinata (2018) juga memberi hasil berupa peningkatan kategori tinggi untuk kompetensi menjelaskan fenomena secara ilmiah serta sedang untuk menafsirkan data dan bukti secara ilmiah. Field trip memang memberi hasil lebih baik di topik ekosistem, tapi kami memandang bahwa strategi tersebut tidak cocok diterapkan di topik plantae dan animalia. Hal ini terjadi karena konten pembelajaran plantae dan animalia berupa organisme tertentu akan tetap bermakna bagi siswa ketika diamati di laboratorium tanpa harus melakukan field trip. Sedangkan konten pembelajaran ekosistem mempelajari interaksi, baik interaksi antar makhluk hidup maupun antara makhluk hidup dengan lingkungannya, sehingga membutuhkan pembelajaran dengan menggunakan field trip (Dinata, 2018).

Perbandingan dengan beberapa hasil penelitian lain memberi pesan bahwa guru selayaknya mengerti karakteristik topik pelajaran, keterampilan yang hendak dilatih dalam pembelajaran, serta keadaan siswa agar proses dapat dilaksanakan secara maksimal guna memperoleh hasil optimal.

Terdapat pendapat yang menyebut bahwa pembelajaran sebaiknya berorientasi terhadap proses bukan hasil pembelajaran. Kami menyangkal pendapat ini dengan memilih pembelajaran yang berorientasi terhadap hasil. Hasil optimal secara konsisten tentu dapat diperoleh melalui proses maksimal yang dibiasakan. Agar hasil yang diperoleh tidak sia-sia, orientasi pembelajaran perlu diarahkan terhadap literasi saintifik bukan sekadar meningkatkan aspek kognitif seperti HOTS (higher order of thinking skill) apalagi sekadar lulus ujian nasional. Sehingga pembelajaran yang dialami oleh siswa tidak sia-sia ketika sudah menyelesaikan pendidikan di sekolah (Si'ayah, 2010).

$$
\text { Secara keseluruhan, dapat }
$$
disampaikan bahwa penerapan pendekatan saintifik dalam pembelajaran biologi efektif untuk melatih literasi saintifik. Pendekatan saintifik dipandang cocok digunakan untuk melatih kompetensi literasi saintifik karena siswa dibiasakan untuk menggunakan metode ilmiah dalam memperoleh informasi. Hal ini membuat pembelajaran lebih berupaya untuk memupuk keterampilan ketimbang menumpuk pengetahuan. Beberapa perbandingan tersebut sekaligus menunjukkan bahwa tidak ditemukan perbedaan menyolok dengan beragam model pembelajaran. Dengan demikian, melalui penelitian ini kami belum dapat menentukan model terbaik untuk digunakan dalam pembelajaran IPA termasuk biologi. Sehingga kami menganggap bahwa setiap model dapat digunakan dalam pembelajaran IPA selama tidak mengabaikan kegiatan pengamatan (observation) dan/atau peramalan (eksperiment) yang merupakan karakteristik IPA, yakni biologi dan fisika.

\section{Simpulan}

Secara keseluruhan penerapan pendekatan saintifik dalam pembelajaran biologi berorientasi literasi saintifik memiliki keefektifan di kategori sedang dengan nilai sebesar 0,548. Hasil ini menunjukkan bahwa pendekatan saintifik bisa menjadi sarana untuk melatih kompetensi literasi saintifik. Melalui perbandingan terhadap beberapa penelitian terungkap bahwa tidak ditemukan perbedaan menyolok dengan beragam model pembelajaran. Dengan demikian, kami tidak dapat menemukan model terbaik untuk digunakan dalam pembelajaran IPA termasuk sekalius bukan hanya biologi.

\section{Ucapan Terima Kasih}

Adib Rifqi Setiawan mengucapkan terima kasih kepada semua warga Madrasah Tasywiquth Thullab Salafiyyah (TBS) Kudus yang memberi dukungan pembelajaran aktual; serta Dr. Setiya Utari dan Dr. Kusnadi dari Sekolah Pascasarjana Universitas Pendidikan Indonesia (SPs UPI) Bandung maupun Syarofis Si'ayah, S.Ked. dari Program Studi 
Pendidikan Dokter Universitas Islam Malang (UNISMA) atas dorongan dan bantuan teknis.

\section{Referensi}

Corebima, Aloysius Duran. 2016. Pembelajaran biologi di indonesia bukan untuk hidup. Proceeding Biology Education Conference, 13(1): 8-22. URL:

https://jurnal.uns.ac.id/prosbi/article/vie wFile/5640/5008

Cronbach, Lee J. 1951. Coefficient alpha and the internal structure of tests. Psychometrika, 16: 297-334. DOI: https://dx.doi.org/10.1007/BF02310555

Dinata, Anita Nurlela. 2018. The influence of field trip on high school student's scientific literacy and attitude towards science in ecosystem concept. Assimilation: Indonesian Journal of Biology Education, 1(1): 8-13. DOI: http://dx.doi.org/10.17509/aijbe.v1i1.11 449

Fraenkel, Jack R. \& Wallen, Norman E. 2009. How to design and evaluate research in education (7th ed.). New York. McGraw-Hill Companies.

Koimah, Siti \& Setiawan, Adib Rifqi. 2019. A glance overview of the living environment. Thesis Commons. DOI: https://dx.doi.org/10.31237/osf.io/6wyq4

Marcharis, Dita Alawiyah. (2015). Beban kognitif siswa pada pembelajaran biologi di sma berbasis pesantren. Skripsi Universitas Pendidikan Indonesia. URL: http://repository.upi.edu/20265/

Nissen, Jayson M. 2018.Comparison of normalized gain and cohen's $\mathrm{d}$ for analyzing gains on concept inventories. Physical Review Physics Education Research, 14(1): 010115. DOI: https://dx.doi.org/10.1103/PhysRevPhys EducRes.14.010115

Nurohmah, Eva Fauziah. 2015. Efektivitas pendekatan saintifik dalam meningkatkan hasil dan motivasi belajar siswa smp. Skripsi Universitas

Pendidikan Indonesia. URL: http://repository.upi.edu/22537/

OECD. 2013. Pisa 2015 draft science framework march 2013. Paris: OECD.

OECD. 2018. Pisa 2015 results in focus. Paris: OECD.

Rustaman, Nuryani Y. 2017. Mewujudkan sistem pembelajaran sains/biologi berorientasi pengembangan literasi peserta didik. Dalam Prosiding Seminar Nasional III Tahun 2017 "Biologi, Pembelajaran, dan Lingkungan Hidup Perspektif Interdisipliner": KS.URL: http://research-

report.umm.ac.id/index.php/researchreport/article/download/944/1157

Sawilowsky, Shlomo S. 2009. New Effect size rules of thumb. Journal of Modern Applied Statistical Methods, 8(2): 597599.

URL:

https://digitalcommons.wayne.edu/jmas $\mathrm{m} / \mathrm{vol} 8 / \mathrm{iss} 2 / 26 /$

Setiawan, Adib Rifqi \& Koimah, Siti. 2019. Effective learning and teaching. Thesis Commons.

DOI: https://dx.doi.org/10.31237/osf.io/p42nx

Setiawan, Adib Rifqi. 2017. Penerapan pendekatan saintifik untuk melatihkan literasi saintifik dalam domain kompetensi pada topik gerak lurus di sekolah menengah pertama. Skripsi Universitas Pendidikan Indonesia. URL: http://repository.upi.edu/29074/

Setiawan, Adib Rifqi. 2019. A brief explanation of scientific teaching. INARxiv.

DOI: https://doi.org/10.31227/osf.io/by9sm

Si'ayah, Syarofis. 2010. Pendidikan di indonesia?? what happen??? Open Science Framework. DOI: http://dx.doi.org/10.31219/osf.io/ubg2k

Suwarma, Irma Rahma. 2012. Science education development in Indonesia: curriculum changes from 1947 - 2010, a way to improve education quality in indonesia. Japan Society for Science Education (JSSE) National Seminar, 36: 
381-382.

URL:

https://www.jstage.jst.go.jp/article/jssep/ 36/0/36_381/_pdf

Utari, Setiya, dkk. 2015. Designing science learning for training students' science literacies at junior high school level. International Conference on Mathematics, Science, and Education 2015 (ICMSE 2015): SE. URL: http://icmseunnes.com/2015/wpcontent/uploads/2016/03/82_SE.pdf

Wahyuni, Sri. 2018. Implementasi pendekatan sainstifik pada pelajaran biologi untuk meningkatkan hasil belajar kognitif dan keterampilan sains siswa kelas xi-ipa sma negeri 2 lambandia, kab. kolaka timur- sultra. Jurnal Pendidikan Biologi, 9(2):

47-55.

DOI:

http://dx.doi.org/10.17977/jpb.v9i2.5301 